\title{
A alimentação do prematuro por meio do copo
}

\author{
Cup-feeding of premature newborn children
}

\author{
Ana Carolina de Medeiros Guilherme da Silva ${ }^{1}$, Karla Patrícia Costa Alencar ${ }^{2}$, Lidiane Cristina Barraviera \\ Rodrigues $^{3}$, Viviane Castro de Araújo Perillo ${ }^{4}$
}

\begin{abstract}
RESUMO
Objetivo: Quantificar a proporção de leite perdido na oferta da dieta com copo; o tempo de oferta e analisar se há relação do desperdício e o tempo gasto na ingesta com as variáveis: sexo, dias de vida, idade gestacional corrigida, tempo de sonda orogástrica, tempo de alimentação por via oral, estado de vigília e sinais de estresse. Métodos: Participaram 20 recém-nascidos prematuros, 11 do sexo feminino e nove do masculino. A média de idade gestacional corrigida foi de 36 semanas e o peso na avaliação de 1668 gramas. Os bebês eram alimentados via oral por, no mínimo, dois dias. Seus prontuários foram analisados quanto ao sexo, idade gestacional, peso atual, dias de vida, tempo de alimentação por via oral e tempo de uso de sonda orogástrica para relacionar aos dados da oferta da dieta. Para a administração do leite, o recém-nascido foi posicionado segundo as normas da Organização Mundial de Saúde. O alimento foi ofertado utilizando-se copo descartável de 50 mililitros, uma gaze foi colocada como anteparo e o tempo da oferta mensurado. Posteriormente, a gaze foi pesada. Resultados: Houve diferença estatisticamente significante entre os volumes aceito $(81,5 \%)$ e desperdiçado $(22,8 \%)$ de leite, com maior aceite para o sexo feminino e para os bebês que não apresentaram sinais de estresse. O tempo médio de ingestão da dieta foi de 416 segundos. Conclusões: Os recém-nascidos pré-termo do sexo feminino aceitaram maior volume de leite, e quanto menor a exposição aos fatores estressantes, maior o aceite da dieta. O tempo médio gasto para ingestão da dieta não foi influenciado pelas variáveis analisadas.
\end{abstract}

Descritores: Recém-nascido; Prematuro; Alimentação; Lactente; Métodos de alimentação

\section{INTRODUÇÃO}

Ao nascer o neonato apresenta algumas características que predominam e determinam habilidades funcionais até por volta dos quatro a seis meses de vida. O recém-nascido pré-termo apresenta imaturidade global, havendo dificuldade para sugar ${ }^{(1)}$, permanecer em estado de alerta, com presença de reflexos orais incompletos ou até ausentes, apresentando tônus predominantemente extensor ${ }^{(2)}$. Por conseguinte, poderá apresentar maior risco de intercorrências durante esse período dependendo de sua maturidade, peso ao nascimento e do tipo e intensidade dos fatores que atuaram durante a sua vida intrauterina, fazendo com que comumente o prematuro receba, em algum momento de sua internação, alimentação com o uso do copo. Isso acontece, pois o desenvolvimento que deveria ocor-

Trabalho realizado no curso de Fonoaudiologia da Faculdade São Lucas Porto Velho (RO), Brasil.

(1) Fonoaudióloga clínica - Porto Velho (RO), Brasil.

(2) Fonoaudióloga clínica - Porto Velho (RO), Brasil.

(3) Mestre, Professora do Curso de Fonoaudiologia da Faculdade São Lucas - Porto Velho (RO), Brasil.

(4) Mestre, Professora do Curso de Fonoaudiologia da Faculdade São Lucas - Porto Velho (RO), Brasil.

Endereço para correspondência: Viviane Castro de Araújo Perillo. R. Padre Chiquinho, 779/203, Pedrinhas, Porto Velho - RO, CEP: 78903-038. E-mail: perilloviviane@ hotmail.com

Recebido em: 11/9/2008; Aceito em: 27/12/2008 rer ainda intra-útero nos recém-nascidos pré-termos (RNPTs) ficou incompleto, e por este motivo estes bebês, muitas vezes, irão precisar da ajuda de uma equipe com vários profissionais para adaptar-se ao seu novo meio: o externo ${ }^{(3)}$.

A idade gestacional, como critério isolado, é um indicador de prontidão considerado pobre para a sucção, porque há entre os bebês pré-termo uma considerável variabilidade, uma vez que alguns podem iniciar a alimentação oral com 32 semanas, enquanto outros só estarão prontos a partir da $36^{\mathrm{a}}$ semana $^{(4)}$.

No neonato, a habilidade de sucção é considerada uma atividade flexora que facilita a alimentação bem sucedida. Para tanto o bebê deve obter uma postura apropriada e fisiológica, chamada de "enrolamento". O padrão de sucção (suckling), realizado pelo bebê recém nascido (RN) é um padrão primitivo, que consiste em movimentos de língua ântero-posteriores. Os lábios permanecem frouxos em volta do bico e há movimentos combinados de abertura e fechamento da mandíbula ${ }^{(5)}$.

Em um estudo com recém-nascidos verificou-se que o aleitamento natural exclusivo favorece a sucção normal e o aleitamento misto induz alterações na sucção, podendo levar à ineficiência do padrão motor-oral da criança. É por este motivo que o desenvolvimento motor-oral adequado influencia na evolução nutricional do RN, permitindo a adequada transição alimentar, de modo que a criança tenha condições de receber os alimentos certos na idade adequada ${ }^{(6)}$.

Além da função de sucção ser a responsável pela nutri- 
ção do RN que se alimenta por via oral, do ponto de vista fonoaudiológico, é por intermédio dessa função que ocorre o desenvolvimento do sistema sensório-motor oral, ou seja, dos órgãos fonoarticulatórios: lábios, língua, bochechas, mandíbula, palatos mole e duro, arcadas dentárias, dentes e musculatura oral e das funções de mastigação, deglutição e respiração ${ }^{(1)}$.

A sucção desempenha um papel fundamental na vida dos recém nascidos em seus primeiros meses de vida, seja pela possibilidade de acalmia propiciada por ela, seja por sua função primária de obtenção do alimento ${ }^{(5,7)}$.

$\mathrm{O}$ aleitamento materno é o mais indicado, pois promove o pleno crescimento e desenvolvimento da criança, sendo fundamental para a nutrição e proteção do lactente ${ }^{(8)}$.

Quando o recém nascido pré-termo apresentar incoordenação entre a sucção, deglutição e respiração, será indicada alimentação intermitente através da sonda naso ou orogástrica ${ }^{(9)}$.

Atualmente, com os novos conhecimentos dos efeitos danosos da utilização dos bicos, tais como: contaminação bacteriana, manipulação inadequada, entre outros, na transição da dieta por sonda orogástrica ou nasogástrica para a via oral utiliza-se o copinho ou a xícara ${ }^{(10)}$. O uso do copo como método artificial seguro de alimentar crianças pré-termo e de baixo peso tem sido descrito por alguns autores e recomendado pela Organização Mundial de Saúde ${ }^{(11)}$.

A alimentação por copinho está associada a um aumento significativo do aleitamento materno exclusivo em prematuros, no momento da alta hospitalar; entretanto, o período de internação desses neonatos é mais prolongado. Há que se lembrar também, que, apesar dos recém nascidos pré-termo permanecerem fisiologicamente estáveis durante a alimentação com copo, é questionado se esse método é eficaz para desenvolver o movimento de língua e mandíbula necessário para alimentação por seio; sem esquecer também do risco de que a ingestão real de leite possa ser menor que a desejada, em função das perdas por derramamento ${ }^{(12)}$.

A fim de avaliar a atividade muscular dos músculos envolvidos na sucção no seio materno, mamadeira e no copo (masseter, bucinador e temporal), um estudo utilizou a eletromiografia de superfície durante a amamentação de lactentes por diferentes métodos (aleitamento materno exclusivo, aleitamento misto com complemento por mamadeira e aleitamento exclusivo, mas com uso do copo durante o exame). Verificou que as semelhanças entre a atividade muscular do grupo de aleitamento materno e aleitamento por copo permitem sugerir o uso do copo como método alternativo na alimentação de lactentes, ao contrário do aleitamento por mamadeira, devido à hiperfunção do músculo bucinador, podendo resultar em alterações motoras orais e das funções neurovegetativas ${ }^{(13)}$.

O objetivo do método com uso do copo é evitar o contato do bebê com outros bicos que não o do peito, evitando a confusão e favorecer o aleitamento materno ${ }^{(10)}$.

A forma como o leite é oferecido para o recém nascido prétermo também é uma variável importante a ser considerada ${ }^{(14)}$. Por isso, os profissionais da saúde devem estar bem orientados sobre o uso do copo e o volume de leite administrado, pois estas orientações são fundamentais para o sucesso da administração adequada da dieta no copinho, principalmente no que se refere à posição do bebê $\hat{e}^{(15)}$.
Os procedimentos de administração do leite com o uso do copinho devem ser realizados pela mãe/cuidador segurando o bebê em estado de vigília, envolvendo-o em um lençol para que o leite não seja derramado pela movimentação de seus membros superiores. O RN deve estar sentado ou semi-sentado no colo da mãe ou do cuidador. Posteriormente, deve-se encostar a borda do copinho no lábio inferior do bebê, inclinando-o até que o leite toque o seu lábio inferior. É necessário aguardar que o bebê retire o leite, sorvendo-o e, em seguida, o degluta. Não é necessário derramar o leite na boca do $\mathrm{RN}^{(3)}$.

É sabido que alimentação do bebê prematuro não pode ultrapassar 30 minutos, para evitar fadiga, e que a administração deste alimento não seja realizada durante o estado de sonolência ${ }^{(16)}$.

Durante a alimentação do recém-nascido pré-termo (RNPT) pode-se observar comportamento espontâneo ou reativo, sinais de aproximação e de retraimento (estresse) como caretas, mudanças faciais, espirros, bocejos, tosses, náuseas, soluços, choro, redução dos movimentos de sucção, tremor de língua, hipoatividade, movimentos de braços e pernas, cianose das extremidades e perioral, diminuição dos reflexos e olhar fixo. Os sinais de aproximação são: segurar a mão do examinador, levar a mão até a boca, movimentos de preensão, conchegarse, emissão de sons, sugar, reflexo de procura e mãos e pés tocando-se juntos ${ }^{(17)}$.

Surge, a partir de então, uma discussão sobre qual a alternativa viável para alimentar o recém-nascido pré-termo que tem possibilidade de receber alimentação por via oral, mas que, por algum motivo, não pode ser alimentado no seio materno.

Portanto, a proposta desta pesquisa é quantificar a proporção de leite perdido durante a oferta da dieta por meio do copo, mensurar o tempo de oferta da dieta e analisar se há relação do desperdiço e tempo gasto na ingesta com as variáveis: sexo, dias de vida ao nascimento, idade gestacional corrigida, tempo de sonda orogástrica, tempo de alimentação por via oral, estado de vigília e sinais de estresse.

\section{MÉTODOS}

Este estudo foi analisado e aprovado pelo Comitê de Ética em Pesquisa da Faculdade São Lucas, em Porto Velho (RO), sob o n ${ }^{\circ} 209 / 08$.

Inicialmente, foi enviada carta de apresentação e pedido de permissão para entrada na Unidade Neonatal do Hospital de Base Ary Pinheiro por ser a única unidade pública do Estado de Rondônia, além de proporcionar intervenção fonoaudiológica aos recém-nascidos.

As mães dos recém-nascidos foram informadas acerca do caráter científico da pesquisa e assinaram o Termo de Consentimento Livre e Esclarecido, aceitaram e autorizaram, também por escrito, a veiculação das imagens dos seus filhos exclusivamente para este estudo.

Foram incluídos na amostra os recém-nascidos pré-termos que, no momento da avaliação, encontravam-se com idade gestacional corrigida maior ou igual a 34 semanas; peso maior que 1300 gramas; que estivessem sendo alimentados por via oral há, no mínimo, dois dias e que não apresentassem quaisquer alterações neurológicas, pulmonares crônicas, cardiopatia con- 
gênita, má-formação craniofacial e soro positivo para vírus da imunodeficiência humana. Assim, fizeram parte deste estudo 20 crianças que se enquadraram nos critérios determinados.

Com vistas a verificar os critérios de inclusão e exclusão, os prontuários dos neonatos foram analisados quanto: ao sexo, tipo de parto, APGAR, idade gestacional, peso ao nascimento e na data da coleta, dias de vida, ao tempo de alimentação por via oral, tempo de uso de sonda orogástrica e à submissão a suporte respiratório.

Todos os procedimentos foram realizados nos momentos das mamadas do período matutino, estabelecidos pelo serviço da unidade, nos horários das nove e 12 horas.

Os materiais utilizados durante o procedimento foram balança digital (da marca Filizola ${ }^{\circledR}$, modelo Baby, última aferição em 26 de maio de 2008) para pesar 50 centímetros de gaze não estéril utilizada para conter o escape do leite durante a oferta da dieta; copo descartável de 50 mililitros para oferecer a dieta e cronômetro digital (marca Q \& $\mathrm{Q}{ }^{\circledR}$ e modelo Cr2032) para mensurar o tempo que o recém-nascido levava para ingerir o leite.

Para administração da dieta os recém-nascidos foram contidos com um lençol, formando um envoltório para que a movimentação dos seus membros superiores não atrapalhasse o momento no qual o leite seria ofertado. As crianças foram posicionadas nas pernas de uma das pesquisadoras, em posição elevada, sendo as regiões: occipital e cervical, sustentadas com a mão oposta a da oferta da dieta.

Antes da oferta houve o cuidado em despertar os bebês. Após o recém-nascido estar devidamente posicionado, era ministrado o leite por meio do copo, sendo este colocado sutilmente no lábio inferior e inclinado para que o conteúdo apenas tocasse nos lábios, não despejando o leite em sua boca, devendo lambê-lo ou sorvê-lo ${ }^{(18)}$. A contenção, o posicionamento do bebê e o modo como foi realizada a oferta do leite por meio do copo estão representados nas Figuras 1 a 5.

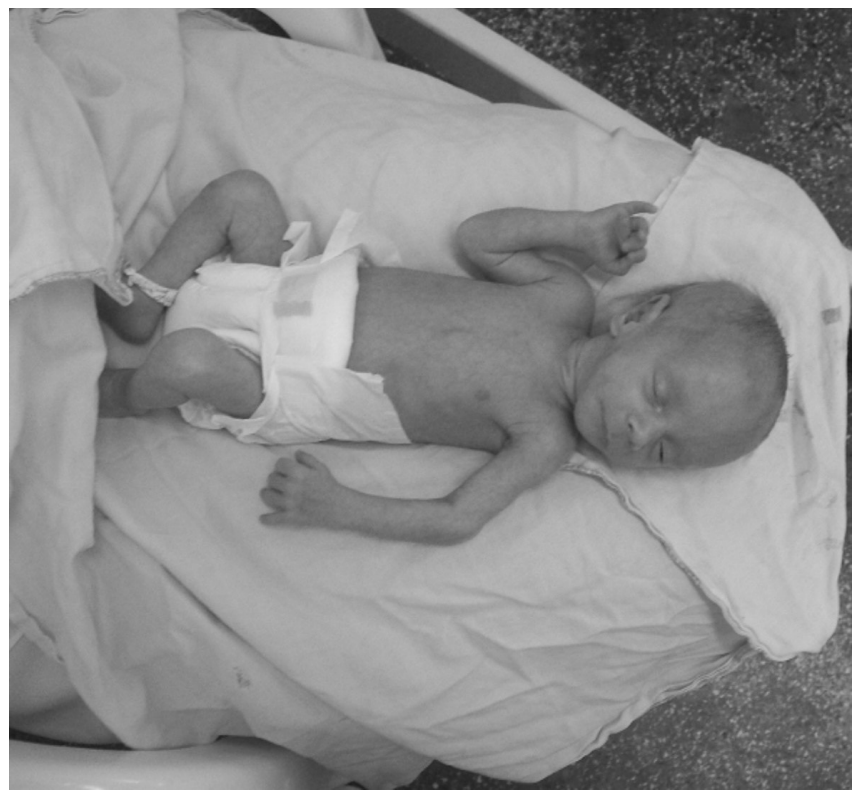

Figura 1. RNPT ainda não contido

FONTE: Silva ACM, Alencar KPC. O uso do copo como instrumento de oferta da dieta ao recém nascido pré-termo [Monografia]. Porto Velho: Faculdade São Lucas; 2008.

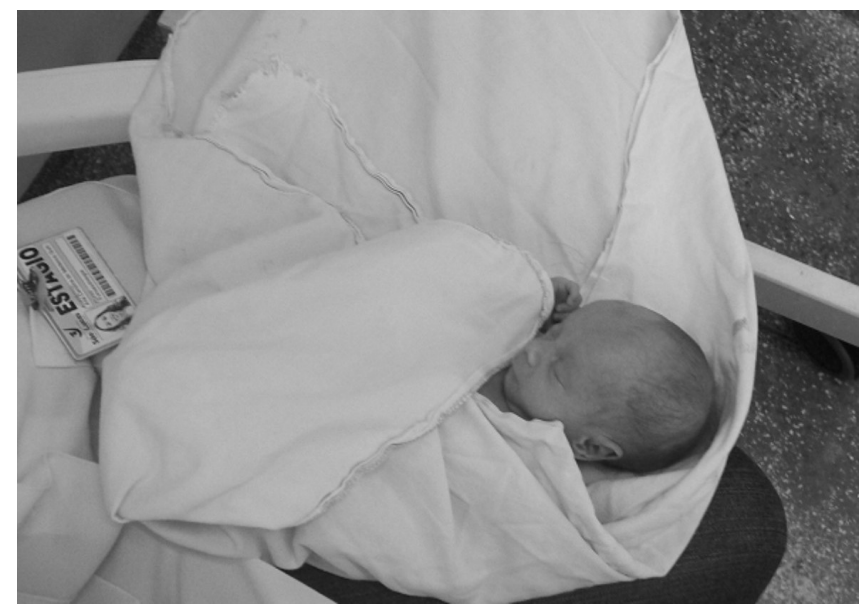

Figura 2. Início da contenção do RNPT

FONTE: Silva ACM, Alencar KPC. O uso do copo como instrumento de oferta da dieta ao recém nascido pré-termo [Monografia]. Porto Velho: Faculdade São Lucas; 2008.

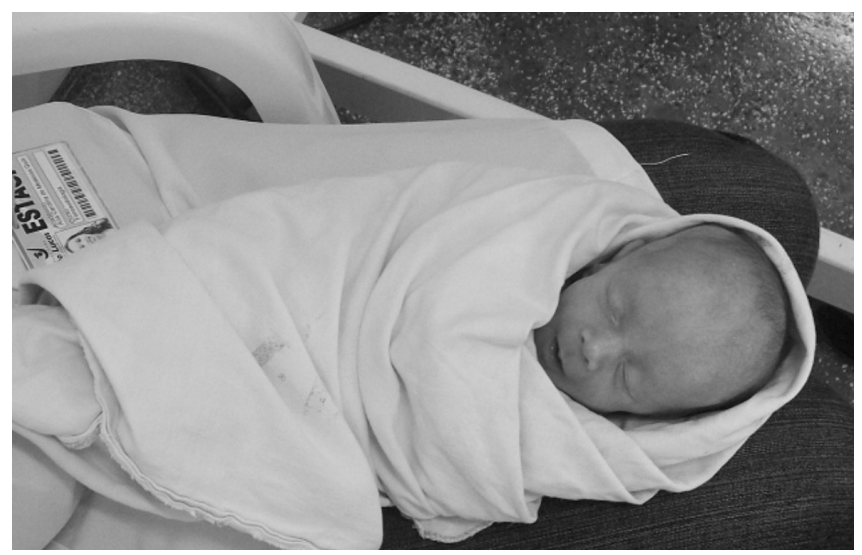

Figura 3. RNPT contido em lençol. Pode-se perceber a não movimentação dos membros.

FONTE: Silva ACM, Alencar KPC. O uso do copo como instrumento de oferta da dieta ao recém nascido pré-termo [Monografia]. Porto Velho: Faculdade São Lucas; 2008.

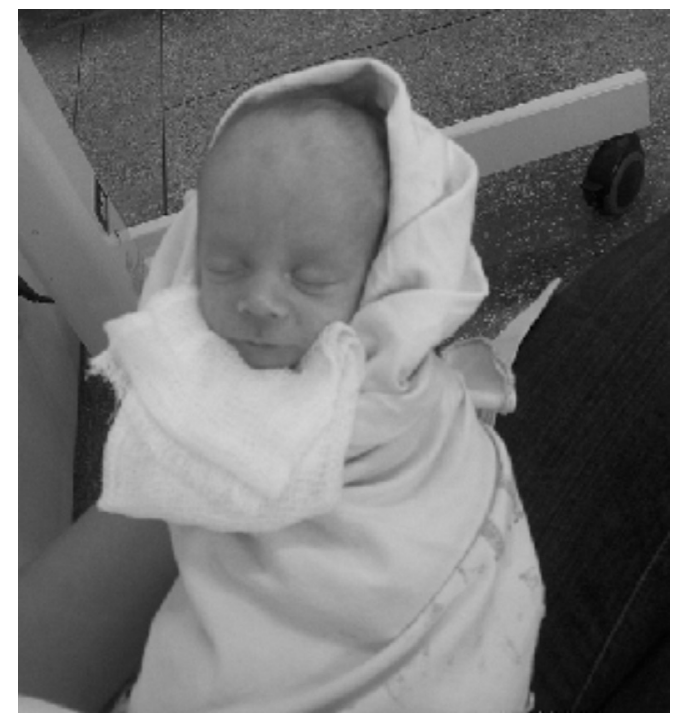

Figura 4. RNPT posicionado (semi-sentado) para a administração do leite por meio do copo. A gaze é utilizada como anteparo.

FONTE: Silva ACM, Alencar KPC. O uso do copo como instrumento de oferta da dieta ao recém nascido pré-termo [Monografia]. Porto Velho: Faculdade São Lucas; 2008. 


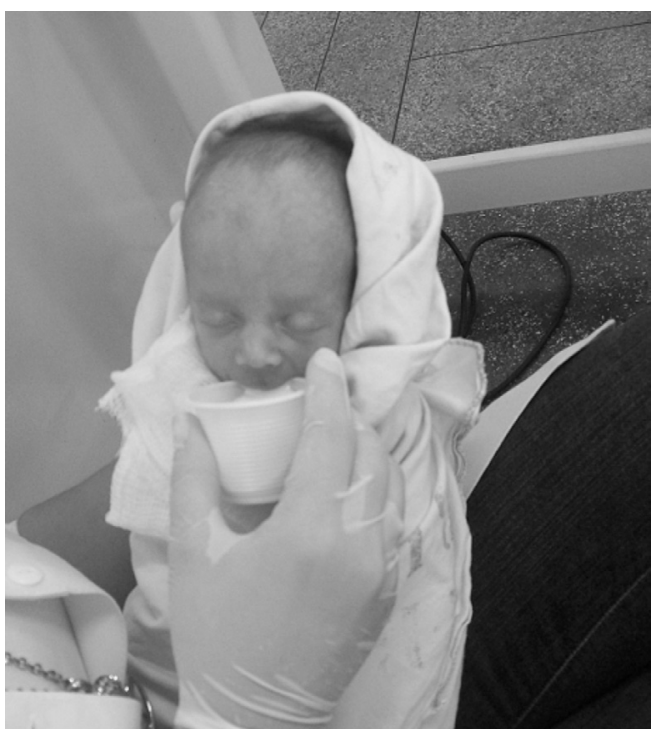

Figura 5. Borda do copo encostado no lábio inferior do RNPT. Presença do ato de sorver.

FONTE: Silva ACM, Alencar KPC. O uso do copo como instrumento de oferta da dieta ao recém nascido pré-termo [Monografia]. Porto Velho: Faculdade São Lucas; 2008.

A oferta seria interrompida nos casos em que os recémnascidos apresentassem engasgos, cianose ou fadiga; contudo, não houve tais intercorrências.

A dieta oferecida correspondia à prescrição diária do médico pediatra (leite materno, leite humano pasteurizado ou leite artificial) e era disponibilizada pelo lactário da unidade. $\mathrm{O}$ mesmo era transferido para o copo descartável de 50 mililitros.

A gaze foi pesada antes e após a oferta e colocada na altura do colo do bebê para conter o leite que poderia ser desperdiçado.

A dieta foi oferecida pelas duas pesquisadoras devidamente treinadas.

Considerou-se início da ingesta o toque das bordas do copo no lábio inferior do recém-nascido e o término, o aceite total ou parcial do leite. Os recém-nascidos eram entregues às suas genitoras que eram orientadas a aguardar o bebê eructar. Nos casos em que as mães não estavam presentes, as pesquisadoras realizavam tal procedimento e, finalmente, o bebê era colocado em seu leito.

Para análise dos dados considerou-se quatro valores da dieta: a prescrita, a aceita, a ingerida e a desperdiçada.

A dieta prescrita referiu-se àquela indicada pelo pediatra diariamente, correspondente ao que era administrado ao RN no intervalo de três horas. A dieta que o neonato recebia, independente do valor prescrito foi denominada dieta aceita. Entretanto, não necessariamente correspondia ao volume ingerido, já que poderia haver escape do leite anteparado pela gaze. Portanto, o valor ingerido foi o resultante da diferença entre a quantidade que foi aceita e a que foi acumulada na gaze (a dieta desperdiçada).

Assim, foram realizadas as seguintes análises: (1) comparação entre o que foi aceito e desperdiçado pelo RN; (2) correlação da proporção do que foi aceito e desperdiçado com as variáveis sexo, dias de vida, peso ao nascimento, idade gestacional corrigida, tempo de sonda orogástrica, tempo de alimentação por via oral, estado de vigília (alerta e sonolência) (19) e sinais de estresse (sudorese, batimento de asas do nariz, alteração na mímica facial, hiperextensão cervical e sonolência); (3) correlação do tempo de ingesta da dieta ofertada com as variáveis supracitadas.

Para a análise dos dados, foram utilizados os seguintes testes estatísticos: (1) Mann-Whitney; (2) Correlação de Spearman; (3) Teste de correlação ${ }^{(20)}$. Foi definido para este estudo o nível de significância estatística de p-valor $\leq 0,05$ (5\%).

\section{RESULTADOS}

Após coletados os dados desta pesquisa, pôde-se constatar que, das 20 crianças avaliadas, 11 eram do sexo feminino e nove do sexo masculino.

As Tabelas 1 a 5 referem-se às comparações das proporções e correlação dos volumes: aceito e desperdiçado entre as variáveis: sexo, dias de vida ao nascimento, idade gestacional corrigida, tempo de sonda orogástrica, tempo de alimentação por via oral, estado de vigília e sinais de estresse.

Tabela 1. Dados estatísticos do volume aceito e desperdiçado

\begin{tabular}{lcc}
\hline Dados estatísticos & Volume aceito & Volume desperdiçado \\
\hline Média & $81,5 \%$ & $22,8 \%$ \\
Mediana & $88,6 \%$ & $21,4 \%$ \\
Desvio Padrão & $20,0 \%$ & $14,3 \%$ \\
CV & $24,5 \%$ & $62,6 \%$ \\
Q1 & $62,3 \%$ & $14,9 \%$ \\
Q3 & $100,0 \%$ & $25,0 \%$ \\
Mínimo & $45,7 \%$ & $0,0 \%$ \\
Máximo & $100,0 \%$ & $58,8 \%$ \\
N & 20 & 20 \\
IC & $8,8 \%$ & $6,2 \%$ \\
Valor de p & & $<0,001^{*}$ \\
\hline
\end{tabular}

Teste estatístico: Mann-Whitney

Legenda: * = valor estatisticamente significante; $\mathrm{CV}=$ coeficiente de variação; Q1 = primeiro quartil; $\mathrm{Q} 3$ = terceiro quartil; $\mathrm{N}$ = número da amostra; IC = intervalo de confiança

Percebe-se que existe diferença estatisticamente significante entre a proporção dos volumes aceito e desperdiçado, na qual se pode notar que a proporção de aceite é maior do que o desperdício. Entretanto, observa-se que a dieta prescrita não é totalmente aceita e o que é aceito não corresponde ao ingerido.

A quantidade ingerida é o resultado do volume aceito subtraído do desperdiçado. Considerando a média, pode-se inferir que a quantidade ingerida é maior que $58,7 \%$ da quantidade prescrita.

Dessa forma, o neonato pode não estar se beneficiando de todo o valor energético indicado no volume total da dieta.

Na Tabela 2 pode-se constatar que o sexo e os sinais de estresse interferem no aceite da dieta de forma estatisticamente significante.

Há tendências significantes entre o tempo de via oral e a quantidade da dieta aceita e em relação ao peso do $\mathrm{RN}$ na avaliação e a dieta desperdiçada. 
Tabela 2. Resultado da correlação dos volumes das dietas e as variáveis estudadas

\begin{tabular}{lcccc}
\hline Variáveis & \multicolumn{2}{c}{ Volume aceito } & \multicolumn{2}{c}{ Volume desperdiçado } \\
\cline { 2 - 5 } & Correlação & Valor de $p$ & Correlação & Valor de $p$ \\
\hline Sexo & $-61,5 \%$ & $0,004^{*}$ & $17,5 \%$ & 0,460 \\
Dias de vida & $28,1 \%$ & 0,231 & $-17,6 \%$ & 0,457 \\
Peso na avaliação & $-13,0 \%$ & 0,585 & $-40,2 \%$ & $0,079 \#$ \\
Idade gestacional corrigida & $34,8 \%$ & 0,132 & $-15,4 \%$ & 0,516 \\
Tempo de sonda orogástrica & $27,0 \%$ & 0,249 & $-18,4 \%$ & 0,437 \\
Tempo de via oral & $37,9 \%$ & $0,099 \#$ & $-35,3 \%$ & 0,127 \\
Estado de vigília & $13,2 \%$ & 0,578 & $0,0 \%$ & 1,000 \\
Sinais de estresse & $-46,4 \%$ & $0,039^{*}$ & $8,7 \%$ & 0,715 \\
\hline
\end{tabular}

Teste estatístico: Correlação de Spearman e Teste de Correlação

Legenda: * = valor estatisticamente significante; \# = valor que tende a ser significativo

Tabela 3. Dados estatísticos do volume aceito e desperdiçado dos diferentes sexos

\begin{tabular}{lcccc}
\hline Dados estatísticos & \multicolumn{2}{c}{ Volume aceito } & \multicolumn{2}{c}{ Volume desperdiçado } \\
\cline { 2 - 5 } & Fem & Masc & Fem & Masc \\
\hline Média & $91,9 \%$ & $68,7 \%$ & $23,2 \%$ & $22,2 \%$ \\
Mediana & $100,0 \%$ & $60,6 \%$ & $16,7 \%$ & $25,0 \%$ \\
Desvio padrão & $14,2 \%$ & $19,1 \%$ & $14,1 \%$ & $15,3 \%$ \\
CV & $15,4 \%$ & $27,7 \%$ & $60,7 \%$ & $68,8 \%$ \\
Q1 & $88,6 \%$ & $57,1 \%$ & $14,7 \%$ & $20,0 \%$ \\
Q3 & $100,0 \%$ & $71,4 \%$ & $23,9 \%$ & $25,0 \%$ \\
N & 11 & 9 & 11 & 9 \\
IC & $8,4 \%$ & $12,5 \%$ & $8,3 \%$ & $10,0 \%$ \\
Valor de p & \multicolumn{2}{c}{$0,007^{*}$} & \multicolumn{2}{c}{0,445} \\
\hline
\end{tabular}

Teste estatístico: Mann-Whitney

Legenda: * = valor estatisticamente significante; CV = coeficiente de variação; Q1 = primeiro quartil; $\mathrm{Q} 3$ = terceiro quartil; $\mathrm{N}=$ número da amostra; IC = intervalo de confiança

Como se pôde observar na Tabela 2, há correlação entre o sexo e o aceite da dieta; entretanto, é na Tabela 3 que se verifica a diferença estatisticamente significante entre os sexos na proporção do volume aceito, sendo que os $\mathrm{RN}$ do sexo feminino aceitam maior volume da dieta do que os do sexo masculino.

Ao analisar a Tabela 4, verifica-se que não existe diferença estatisticamente significante entre os estados de vigília (sonolência e alerta), tanto para o volume da dieta aceita quanto desperdiçada.

Diante disso pode-se afirmar que o estado de vigília do RN não interferiu na quantidade de volume aceito e desperdiçado.

Na Tabela 5, há uma diferença estatisticamente significante entre apresentar ou não sinais de estresse em relação à proporção de dieta aceita. Ou seja, os RN que apresentaram sinal de estresse possuíram menor aceitabilidade da dieta e os que não apresentaram, aceitaram o volume total do leite oferecido. É importante frizar que das 20 crianças avaliadas apenas quatro não apresentaram sinal de estresse.

$\mathrm{Na}$ Tabela 6 verifica-se que as correlações entre todas as variáveis e o tempo total de ingesta não são estatisticamente
Tabela 4. Dados estatísticos do volume aceito e desperdiçado para a variável estado de vigília

\begin{tabular}{lcccc}
\hline Dados estatísticos & \multicolumn{2}{c}{ Volume aceito } & \multicolumn{2}{c}{ Volume desperdiçado } \\
\cline { 2 - 5 } & Alerta & Sonolência & Alerta & Sonolência \\
\hline Média & $85,1 \%$ & $79,1 \%$ & $25,3 \%$ & $21,1 \%$ \\
Mediana & $100,0 \%$ & $74,3 \%$ & $19,7 \%$ & $21,9 \%$ \\
Desvio padrão & $20,7 \%$ & $20,0 \%$ & $19,6 \%$ & $10,0 \%$ \\
CV & $24,3 \%$ & $25,3 \%$ & $77,2 \%$ & $47,4 \%$ \\
Q1 & $62,3 \%$ & $65,0 \%$ & $14,9 \%$ & $16,1 \%$ \\
Q3 & $100,0 \%$ & $100,0 \%$ & $31,3 \%$ & $25,0 \%$ \\
N & 8 & 12 & 8 & 12 \\
IC & $14,3 \%$ & $11,3 \%$ & $13,6 \%$ & $5,6 \%$ \\
Valor de p & \multicolumn{3}{c}{0,564} & \multicolumn{3}{c}{1,000} \\
\hline
\end{tabular}

Teste estatístico: Mann-Whitney

Legenda: CV = coeficiente de variação; Q1 = primeiro quartil; Q3 = terceiro quartil; $\mathrm{N}$ = número da amostra; $\mathrm{IC}$ = intervalo de confiança.

Tabela 5. Dados estatísticos do volume aceito e desperdiçado para o variável estresse

\begin{tabular}{lcccc}
\hline Dados estatísticos & \multicolumn{3}{c}{ Volume aceito } & \multicolumn{2}{c}{ Volume desperdiçado } \\
\cline { 2 - 5 } & Sim & Não & Sim & Não \\
\hline Média & $76,9 \%$ & $100,0 \%$ & $21,9 \%$ & $26,2 \%$ \\
Mediana & $71,4 \%$ & $100,0 \%$ & $23,3 \%$ & $15,9 \%$ \\
Desvio padrão & $19,8 \%$ & $0,0 \%$ & $12,6 \%$ & $21,8 \%$ \\
CV & $25,7 \%$ & $0,0 \%$ & $57,6 \%$ & $82,9 \%$ \\
Q1 & $60,5 \%$ & $100,0 \%$ & $16,1 \%$ & $14,9 \%$ \\
Q3 & $100,0 \%$ & $100,0 \%$ & $25,0 \%$ & $27,2 \%$ \\
N & 16 & 4 & 16 & 4 \\
IC & $9,7 \%$ & $-x-$ & $6,2 \%$ & $21,3 \%$ \\
Valor de p & \multicolumn{2}{c}{$0,043^{*}$} & \multicolumn{3}{c}{0,704} \\
\hline
\end{tabular}

Teste estatístico: Mann-Whitney

Legenda: * = valor estatisticamente significante; $\mathrm{CV}$ = coeficiente de variação; $\mathrm{Q} 1$ = primeiro quartil; $\mathrm{Q} 3$ = terceiro quartil; $\mathrm{N}=$ número da amostra; $\mathrm{IC}=$ intervalo de confiança; - $\mathrm{x}$ - = não foi possível utilizar o teste estatístico

significantes, ou seja, o tempo total da ingesta não foi influenciado pelas variáveis relacionadas. 
Tabela 6. Resultado da correlação do tempo total de ingesta com os volumes prescrito, aceito e desperdiçado e as variáveis: sexo, peso na avaliação, idade gestacional corrigida, tempo de via oral, estado de vigília e sinais de estresse

\begin{tabular}{lcc}
\hline Variáveis & \multicolumn{2}{c}{ Tempo total } \\
\cline { 2 - 3 } & Correlação & Valor de $\mathrm{p}$ \\
\hline Dieta prescrita & $-11,1 \%$ & 0,640 \\
Dieta aceita & $-12,8 \%$ & 0,592 \\
Dieta desperdiçada & $22,7 \%$ & 0,337 \\
Sexo & $-7,8 \%$ & 0,742 \\
Peso na avaliação & $-17,6 \%$ & 0,458 \\
Idade gestacional corrigida & $-11,6 \%$ & 0,626 \\
Tempo de via oral & $-20,7 \%$ & 0,382 \\
Estado de vigília & $9,7 \%$ & 0,683 \\
Sinais de estresse & $-28,2 \%$ & 0,229
\end{tabular}

Teste estatístico: Correlação de Spearman

\section{DISCUSSÃO}

Nota-se na Tabela 1 que o volume ingerido pelos RN corresponde, em média, a $58 \%$ do que foi prescrito aos mesmos. O tipo de utensílio utilizado durante a oferta, demonstrando inabilidade motora oral do neonato para o uso do copo e a forma de manipulação e administração da dieta, posto que cada RN tem seu padrão de desenvolvimento neuromotor influenciado pela prematuridade, podem ter contribuído para o desperdício de leite. Talvez houvesse uma resposta distinta, caso a dieta fosse ofertada com o uso de outro utensílio. Além disso, não se pode deixar de comentar que consequências peri e pós natais; o nível de consciência e a rotina da unidade considerada estressante, com manipulações constantes, dolorosas, uso de iluminação e estímulos sonoros excessivos ${ }^{(4,6,16-17)}$, também interferem no comportamento dos RN durante a alimentação.

Em um extenso apanhado bibliográfico ${ }^{(21)}$, que discorreu sobre a implicação do copo para a alimentação do RNPT, observou-se que quantidade média de derramamento do leite é de $38,5 \%$ do volume total da dieta. O desperdício no presente estudo foi de $42 \%$, ou seja, discretamente superior àquele, fato que suscita o questionamento de que o copo seja um utensílio eficiente para esta clientela.

Outro estudo, que descreve o padrão de alimentação de RNPT com o uso do copinho, observou que $57,5 \%$ apresentaram derramamento de leite, com uma média de desperdício de $12 \%{ }^{(21)}$. Na presente pesquisa, $60 \%$ dos neonatos apresentaram derramamento do leite, valor que corrobora com a autora; entretanto, o volume do desperdício não foi coincidente, já que permeou $42 \%$.

Nas Tabelas 2, 3 e 5 pode-se constatar que o sexo e os sinais de estresse interferem no aceite da dieta de forma estatisticamente significante e houve tendências de significância estatística para o tempo de via oral relacionado à quantidade da dieta aceita, assim como em relação ao peso do RN na avaliação à quantidade da dieta desperdiçada.

Não constam na literatura estudos que demonstram diferença relacionada ao padrão motor oral ou habilidade quanto ao uso do copo entre sexos. A amostra deste estudo não apresenta diferença numérica entre os sexos que justifique o resultado obtido, sendo $55 \%$ neonatos do sexo feminino e $45 \%$ do masculino. Certamente, fazem-se necessários estudos que corroborem este dado.

Na Tabela 5 percebe-se que apenas quatro RN não apresentaram sinais de estresse e que os mesmos foram os únicos que aceitaram o volume total da dieta. O RNPT apresenta restrições devido a sua imaturidade global e, por consequência, está mais suscetível a receber estímulos, podendo ocorrer menor tolerância à manipulação. Sendo assim, é imprescindível que haja maior atenção por parte da equipe aos possíveis sinais comportamentais que o bebê possa apresentar ${ }^{(22)}$.

Mesmo não havendo significância estatística, o tempo de via oral parece influenciar o volume da dieta aceita pelo $\mathrm{RN}$ e o peso do bebê também pode interferir no quanto o mesmo desperdiça de leite. $\mathrm{O}$ peso e a idade gestacional não são preditivos para a alimentação por via oral ao recém-nascido pré-termo $^{(23)}$.

O estado de vigília não foi estatisticamente significante para o aceite e o desperdício da dieta (Tabela 4), mas não podemos generalizar para os demais estados de consciência, posto que na amostra estudada as crianças permaneceram em sonolência ou alerta, pois houve o cuidado de despertá-las anteriormente à oferta da dieta. Observou-se em um estudo que o estado de consciência foi a inadequação, mais frequentemente observada pelos fonoaudiólogos nas unidades neonatais no momento de oferecer o copinho ${ }^{(16)}$.

O tempo de ingesta da dieta não foi influenciado por nenhuma variável relacionada (Tabela 6). Entretanto, os 416 segundos (sete minutos e 33 segundos) para um volume médio de 33 mililitros obtidos nesta pesquisa estão abaixo do valor citado pela literatura. Um estudo referiu que a duração média do tempo de alimentação com o copinho foi de 15 minutos, para um volume de 4,6 mililitros ${ }^{(24)}$. Outra pesquisa obteve média de ingesta de três mililitros em dois minutos para RNPT em transição para via oral ${ }^{(22)}$. É valido ratificar que todos os neonatos do presente trabalho foram acompanhados fonoaudiologicamente e que o tempo médio de via oral foi de cinco dias.

A unidade neonatal da qual as 20 crianças fazem parte compreende o único serviço público de referência desta natureza no Estado de Rondônia, sendo responsável pelo atendimento não só deste Estado, mas do Acre, Mato Grosso, Amazonas e, também, de países vizinhos como a Bolívia.

Oferece cuidados interdisciplinares, dentre os quais de enfermagem, fisioterapia, fonoaudiologia, psicologia, nutrição e social. A intervenção fonoaudiológica preconiza a transição da alimentação para via oral, além do apoio e incentivo ao aleitamento materno e estimulação psicomotora e de linguagem.

Neste serviço não é aceito o uso de mamadeira ou chupeta; entretanto, não é disponibilizado à mãe o contato permanente com o RN, sendo este fator dificultador do aleitamento materno, na ocasião da liberação da alimentação por via oral.

É sabido que o tempo prolongado de hospitalização do RNPT acarreta consequências negativas para o aleitamento materno exclusivo, agravado pela falta de condições estruturais e da ação direta da equipe que assiste o neonato e sua família. 


\section{CONCLUSÃO}

Após a análise dos resultados deste estudo, pode-se concluir que houve diferença entre o volume aceito e desperdiçado, verificado como desperdício anteparado pela gaze. O sexo feminino aceitou maior volume de leite, e quanto menor a exposição aos fatores de estresse maior o aceite da dieta. Além disso, o tempo para a ingesta da dieta pelos recém-nascidos não foi influenciado pelas variáveis sexo, dias de vida, peso ao nascimento, idade gestacional corrigida, tempo de sonda orogástrica, tempo de alimentação por via oral, estado de vigília ou sinais de estresse.

\begin{abstract}
Purpose: To quantify the milk loss ratio and the length of cup-feeding, and to analyze whether the waste and time expended in ingestion are related to the variables: sex, days of life, corrected gestational age, period of time using orogastric tube, period of time receiving oral feeding, alertness, and signs of stress. Methods: Twenty premature newborn children, 11 female and nine male, participated on this study. The mean corrected gestational age was 36 weeks, and mean weight during evaluation was 1668 grams. The babies were orally fed for, at least, two days. Their medical files were analyzed regarding sex, gestational age, current weight, days of life, period of time receiving oral feeding, and period of time using orogastric tube, in order to relate these data with cup-feeding offer. For cup-feeding, the newborns were positioned according to World Health Organization standards. The milk administration was carried out using disposable 50-milliliters cups; gauze was placed as a shield, and the length of offer was measured. Later, the gauze was weighed. Results: There was a significant statistical difference between the volumes of accepted (81.5\%) and wasted (22.8\%) milk, with more acceptance for female newborns and for the babies who did not present signs of stress. The mean length of cup-feeding was 416 seconds. Conclusion: Female preterm newborns accepted grater milk volume, and the lesser exposition to stressing factors the bigger the acceptance of milk. The mean length of ingestion was not influenced by the variables analyzed.
\end{abstract}

Keywords: Infant, newborn; Infant, premature; Feeding; Infant; Feeding methods

\section{REFERÊNCIAS}

1. Neiva FCB. Sucção em recém-nascidos: algumas contribuições da fonoaudiologia. Pediatria (São Paulo). 2000;22(3):265-70.

2. Andrade ISN, Guedes ZCF. Sucção do recém-nascido prematuro: comparação do método mãe-canguru com os cuidados tradicionais. Rev Bras Saúde Matern Infant. 2005;5(1):61-9.

3. Leone CR, Ramos JLA, Vaz FAC. O recém-nascido pré-termo. In: Marcondes E, Vaz FAC, Ramos JLA, Okay Y. Pediatria básica. 9a. ed. São Paulo: Sarvier; 2002. p. 348-52.

4. Caetano LC, Fujinaga CI, Scochi CGS. Sucção não nutritiva em bebês prematuros: estudo bibliográfico. Rev Latinoam Enferm. 2003;11(2):232-6.

5. Hernandez AM. Atuação fonoaudiológica com recém-nascidos e lactentes disfágicos. In: Hernandez AM, Marchesan IQ. Atuação fonoaudiológica no ambiente hospitalar. Rio de Janeiro: Revinter; c2001.

6. Andrade CRF, Gullo ACP. As alterações do sistema motor oral dos bebês como causa das fissuras/rachaduras mamilares. Pediatria (São Paulo). 1993;15(1):28-33.

7. Souza SL, Castro RM, Nogueira MI. Comportamento alimentar neonatal. Rev Bras Saúde Matern Infant. 2003;3(3):241-6.

8. Alves MC, Araújo VC, Guedes ZCF. Habilidade na utilização dos utensílios copo e canudo por lactentes de 6 a 12 meses de idade. Fono Atual. 2005;8(33):4-10.

9. Araújo KCS, Poyart MCMS, Barros MRM, Lopes JMA, Chiappetta ALML. Os efeitos do controle motor oral na alimentação de prematuros em unidades de terapia intensiva neonatal. Rev CEFAC. 2004;6(4):3827.

10. Lima GMS. Métodos especiais de alimentação: copinho - relactação translactação. In: Rego JD. Aleitamento materno. São Paulo: Atheneu; 2001.

11. Lang S, Lawrence CJ, Orme RL. Cup feeding: an alternative method of infant feeding. Arch Dis Child. 1994;71(4):365-9.

12. Nascimento MBR, Issler $\mathrm{H}$. Aleitamento materno em prematuros: manejo clínico hospitalar. J Pediatr (Rio J). 2004;80(5 Supl):S163-72.
13. Gomes CF, Trezza EMC, Murade ECM, Padovani CR. Surface electromyography of facial muscles during natural and artificial feeding of infants. J Pediatr (Rio J). 2006;82(2):103-9.

14. Aquino RR, Osório MM. Alimentação do recém-nascido pré-termo: métodos alternativos de transição da gavagem para o peito materno [revisão]. Rev Bras Saúde Matern Infant. 2008;8(1):11-6.

15. Lima VP, Melo AM. Uso do copinho no alojamento canguru. Rev CEFAC. 2008;10(1):126-33.

16. Couto DE, Nemr K. Análise da prática da técnica do copinho em hospitais amigos da criança nos estados do Rio de Janeiro e São Paulo. Rev CEFAC. 2005;7(4):448-59.

17. Almeida EC, Modes LC. Avaliação e intervenção fonoaudiológica em recém-nascidos de alto risco com dificuldades na dieta oral. In: Almeida EC, Modes LC. Leitura do prontuário: avaliação e conduta fonoaudiológica com o recém-nato de risco. Rio de Janeiro: Revinter; 2005.

18. Kuehl J. Cup feeding the newborn: what you should know. J Perinat Neonatal Nurs. 1997;11(2):56-60.

19. Brazelton TB. Neonatal behavioral assessment scale. London: William Heinemann Medical Books; 1973.

20. Fonseca JS, Martins GA. Curso de estatística. 6a. ed. São Paulo: Atlas; 1996.

21. Bülher KECB, Limongi SCO. O uso do copinho como método de alimentação de recém-nascidos pré-termo: revisão de literatura. Rev Soc Bras Fonoaudiol. 2004;9(2):116-21.

22. Bühler KECB. Introdução da alimentação via oral com o uso do copinho em recém-nascidos pré-termo: critérios fonoaudiológicos [dissertação]. São Paulo: Faculdade de Medicina da Universidade de São Paulo; 2003.

23. Xavier C. Avaliação da alimentação de recém-nascidos em fase de hospitalização (escala de avaliação motora oral da Irmandade Santa Casa de Misericórdiade São Paulo). Pró-Fono. 1995;7(2):69-74.

24. Dowling DA, Meier PP, DiFiore JM, Blatz M, Martin RJ. Cup-feeding for preterm infants: mechanics and safety. J Hum Lact. 2002;18(1):1320; quis 46-9, 72. Comment in: J Hum Lact. 2002;18(4):333; author reply $333-4$. 